\title{
Tibial lengthening over intramedullary nails
}

R. D. Burghardt,

A. Manzotti, A. Bhave, D. Paley, J. E. Herzenberg

International Center for Limb Lengthening, Rubin Institute for Advanced Orthopedics, Sinai Hospital of Baltimore, Baltimore, Maryland, United States

- R. D. Burghardt, MD, Research Coordinator, Department of Orthopaedics, University Medical Center Hamburg-Eppendorf, Martinistrasse 52, 20246, Hamburg, Germany.

A. Manzotti, MD, Director, Orthopaedic and Traumatological Department, "Luigi Sacco"

Hospital, Via GB Grassi 74; 20157 Milan, Italy.

- A. Bhave, PT, Division Head of Rehabilitation, Rubin Institute for Advanced Orthopedics, Sinai Hospital of Baltimore, 2401 West Belvedere Ave, Baltimore MD 21215, USA.

- D. Paley, MD, FRCSC, Director, Paley Advanced Limb Lengthening Institute, St. Mary's Hospital, Kimmel Building, 901 45th St., West Palm Beach, FL 33407, USA. I. E. Herzenberg, MD, FRCSC, Director, International Center for Limb Lengthening and Director, Pediatric Orthopedics, Sinai Hospital of Baltimore, 2401 West Belvedere Ave, Baltimore MD 21215, USA.

Correspondence should be sent to J. E. Herzenberg; email: jherzenberg@lifebridgehealth.org doi: 10.1302/2046-3758. $51.2000577 \$ 2.00$

Bone Joint Res 2016;5:1-10. Received: 16 September 2015; Accepted: 23 December 2015

\section{Objectives}

The purpose of this study was to compare the results and complications of tibial lengthening over an intramedullary nail with treatment using the traditional Ilizarov method.

\section{Methods}

In this matched case study, 16 adult patients underwent 19 tibial lengthening over nails (LON) procedures. For the matched case group, 17 patients who underwent 19 llizarov tibial lengthenings were retrospectively matched to the LON group.

\section{Results}

The mean external fixation time for the LON group was 2.6 months and for the matched case group was 7.6 months. The mean lengthening amounts for the LON and the matched case groups were $5.2 \mathrm{~cm}$ and $4.9 \mathrm{~cm}$, respectively. The radiographic consolidation time in the LON group was 6.6 months and in the matched case group 7.6 months. Using a clinical and radiographic outcome score that was designed for this study, the outcome was determined to be excellent in 17 and good in two patients for the LON group. The outcome was excellent in $\mathbf{1 4}$ and good in five patients in the matched case group. The LON group had increased blood loss and increased cost. The LON group had four deep infections; the matched case group did not have any deep infections.

\section{Conclusions}

The outcomes in the LON group were comparable with the outcomes in the matched case group. The LON group had a shorter external fixation time but experienced increased blood loss, increased cost, and four cases of deep infection. The advantage of reducing external fixation treatment time may outweigh these disadvantages in patients who have a healthy soft-tissue envelope.

Cite this article: Bone Joint Res 2016;5:1-10.

Keywords: lengthening over nail; tibia; limb lengthening; external fixator; intramedullary nail

\section{Article focus}

- The study compares the results and complications of tibial lengthening using the lengthening over nail (LON) technique with the traditional Ilizarov method.

\section{Key messages}

- LON treatment reduces the duration of treatment with external fixation and has similar outcomes when compared with treatment with the llizarov method.

- The LON group had increased blood loss and increased cost when compared with the llizarov group. The LON group had four cases of deep infection, while the llizarov group did not have any deep infections.

- When patients are carefully selected (e.g., healthy soft-tissue envelope), the advantage of reduced external fixation time may be worth the potential complications.

\section{Strengths and limitations}

- Strengths - this study is the only casematched series of tibial lengthening using LON and the llizarov method.

- Both groups underwent treatment by the same surgeons and at the same centre. 
- Weaknesses - this study is a retrospective review instead of a prospective randomised trial, and we compare two techniques that were used during two different five-year periods.

\section{Introduction}

Gradual distraction with an external fixator is the standard method used for tibial lengthening. ${ }^{1-5}$ External fixator treatment time can be divided into distraction and consolidation phases. During the distraction phase, the limb is lengthened. After the desired lengthening is achieved, the consolidation phase begins. This phase ends when the newly formed bone within the distraction gap has sufficiently healed and the external fixator can be removed without fracture or deformation. In children, the consolidation phase is usually two times longer than the distraction phase; in adults, it is three to four times longer.6,7 Lengthy external fixation treatment time is difficult for patients because of the unwieldy apparatus, the need to maintain clean pin sites constantly, and the discomfort associated with pins as they traverse moving muscles. If the fixator is removed too early, the tibia may fracture, resulting in deformity (malunion).

We previously described a method to reduce the external fixation time by performing a femoral lengthening over nail (LON) procedure. ${ }^{8}$ This technique was adopted by other surgeons and is presented in several scientific studies.9-20

During the index surgery, an osteotomy is performed, an intramedullary nail is inserted and locked proximally, and an external fixator is applied. When the tibia has been lengthened to its predetermined goal, interlocking screws are inserted into the nail and the external fixator is removed. The intramedullary nail stabilises the regenerate bone throughout the consolidation phase, protecting it from bending and fracture. The time to external fixation for patients who have an intramedullary nail previously inserted, therefore, ends at the completion of the distraction phase. The purpose of this study was to evaluate the results and complications of the tibial LON technique and compare these outcomes with traditional Ilizarov tibial lengthening.

\section{Materials and Methods}

To assess and match the level of difficulty of treatment for each patient, we modified a scale from a previous publication $^{8}$ that studied femoral LON. The scale was based on 11 parameters that increase the difficulty and risk of tibial lengthening (Table I); these include age, complexity of the deformity, other levels of treatment in the same bone, any associated lengthening, joint instability, a fixed deformity such as lack of full knee extension, or limitation of knee flexion, ankle movement, joint arthrosis, quality of the bone, quality of the soft tissue, and any medical or medication problems. The pre-operative difficulty level of each lengthening was defined by finding the total score from this scale and labelling it mild (0 to 6 points), moderate ( 7 to 11 points), or severe ( $\geq 12$ points).
The LON group was a consecutive series of patients. Each patient in the LON group was compared with a patient in the matched case group. Patients in the matched case group had Ilizarov external fixation throughout both the distraction and consolidation phases. These patients were selected from a group who had standard Ilizarov tibial lengthenings performed before the new technique by the same surgeons, in the same centre, during a fiveyear period. Patients were selected if they were the best match for the amount lengthened $( \pm 2.5 \mathrm{~cm})$, age ( \pm ten years), aetiology (post-traumatic. developmental, congenital), and severe, moderate, or mild difficulty level. Matching was achieved by tabulating the parameters for the amount lengthened, age, aetiology, and level of difficulty for the 17 patients who had Ilizarov lengthenings and the 16 LON patients. To prevent bias in the matching process, the patients were coded by number without their names, results, or complications. Of the 19 tibial lengthenings, 13 were successfully matched for all four criteria. The other six lengthenings were matched for three out of four criteria.

Evaluation criteria. We modified a tibial lengthening outcome score (Tables II and III) that is based on clinical and radiographic criteria and was used in a prior publication on femoral LON. ${ }^{8}$ These scores were calculated by adding and subtracting point values assessed in the following areas: ankle range of movement (ROM), lengthening, gait, medial proximal tibial angle (MPTA), pain, and activity or work ability. The total score for each case was calculated by adding up the points obtained by using Table II, and then subtracting the value obtained by using Table III. An excellent score constituted a total of 95 to 100 points, a good score was a total of 75 to 94 points, a fair score was a total of 40 to 74 points, and a poor score was less than 40 points.

Operative times, estimated blood loss, and cost of treatment were also compared between the LON and matched case groups.

We modified Paley's complication classification ${ }^{7}$ into the following: grade 1 - problems: difficulties that arise during treatment but are fully resolved non-operatively; grade 2 - obstacles: difficulties that arise during treatment that are fully resolved operatively; grade 3 - sequelae: difficulties that remain after fixator removal. The latter are further subdivided into minor or major categories, depending upon their clinical importance.

Radiographs were obtained for both groups during the consolidation phase and follow-up period. When three of four cortices are intact on the anteroposterior and lateral radiographs, ${ }^{6}$ the bone in the distraction gap is judged to be sufficiently healed. This is defined as the radiographic consolidation end point. For patients in the matched case group, the radiographic consolidation end point marks the time when the external fixator can be removed. Thus, for the matched case group, the definition of the radiographic consolidation time is the same as the definition of the external 
Table I. Difficulty level classification.

\begin{tabular}{|c|c|c|c|c|}
\hline & 0 point & 1 point & 2 points & 3 points \\
\hline Age (yrs) & 5 to 19 & 0 to 4,20 to 29 & 30 to 50 & $>50$ \\
\hline $\begin{array}{l}\text { Complexity of deformity } \\
\text { correction at level of } \\
\text { lengthening }\end{array}$ & None & $\begin{array}{l}\text { Angular }>5^{\circ},<20^{\circ} \text {; rotation }> \\
10^{\circ},<30^{\circ} \text {; translation }<50 \% \\
\text { bone diameter; MAD } 1 \text { to } 3 \mathrm{~cm}\end{array}$ & $\begin{array}{l}\text { Angular }>20^{\circ} ; \text { rotation }>30^{\circ} ; \\
\text { translation }>50 \% \text { bone diameter; } \\
M A D>3 \mathrm{~cm}\end{array}$ & $\begin{array}{l}\text { Combination of deformities at one } \\
\text { level or multilevel deformities }\end{array}$ \\
\hline $\begin{array}{l}\text { Other levels of treatment } \\
\text { in the tibia }\end{array}$ & None & $\begin{array}{l}\text { One additional level, mild } \\
\text { complexity }\end{array}$ & $\begin{array}{l}\text { One additional level, moderate } \\
\text { complexity }\end{array}$ & $\begin{array}{l}\text { Two more additional levels of } \\
\text { deformities or one additional level } \\
\text { of severe complexity }\end{array}$ \\
\hline $\begin{array}{l}\text { Associated lengthening } \\
(\mathrm{cm})\end{array}$ & None & 1 to 3 & 3.1 to 6 & $>6$ \\
\hline Joint instability & None & Grade I: mild instability & $\begin{array}{l}\text { Grade II: moderate instability/ } \\
\text { subluxable }\end{array}$ & $\begin{array}{l}\text { Grade III: fixed subluxation/ } \\
\text { dislocation }\end{array}$ \\
\hline $\begin{array}{l}\text { Lack of knee extension } \\
\text { and/or flexion }\left({ }^{\circ}\right)\end{array}$ & $0 />120$ & 1 to $5 / 100$ to 120 & 6 to $20 / 65$ to 99 & $>20 /<65$ \\
\hline Ankle movement $\left({ }^{\circ}\right)$ & $\begin{array}{l}\text { Ankle arthrodesis/ } \\
>15 \text { dors } /<30 \\
\text { plant }\end{array}$ & $>10$ dors $/<15$ plant & 0 dors $/ 0$ plant & Fixed equinus \\
\hline Joint arthrosis & None & $\begin{array}{l}\text { Marginal osteophytes, } \\
\text { subchondral sclerosis }\end{array}$ & Joint space narrowing & Joint space loss (bone on bone) \\
\hline Bone quality & Normal & $\begin{array}{l}\text { Ollier disease, nonunion, mild } \\
\text { osteoporosis }\end{array}$ & $\begin{array}{l}\text { Radiation, neurofibromatosis, } \\
\text { osteogenesis imperfecta }\end{array}$ & Osteonecrosis, infection \\
\hline Soft-tissue quality & Normal & Spastic, obese, muscular & $\begin{array}{l}\text { Fibrotic, post radiation, small open } \\
\text { wound }\end{array}$ & $\begin{array}{l}\text { Tissue necrosis, infection, large } \\
\text { open wound }\end{array}$ \\
\hline $\begin{array}{l}\text { Medical problems/ } \\
\text { medications }\end{array}$ & None & $\begin{array}{l}\text { Smoking, hypertension, } \\
\text { rheumatoid arthritis or other } \\
\text { systemic arthritis }\end{array}$ & $\begin{array}{l}\text { Diabetes, haemophilia, sickle cell, } \\
\text { mild immunosuppression, bone } \\
\text { inhibiting medications }\end{array}$ & $\begin{array}{l}\text { Moderate immunosuppression, } \\
\text { antimetabolite chemotherapy }\end{array}$ \\
\hline
\end{tabular}

Lengthening planned in the tibia each $\mathrm{cm}$ of lengthening $=1.0$ point

MAD, mechanical axis deviation; dors, dorsiflexion; plant, plantarflexion; mild, 0 to 6 points; moderate, 7 to 11 points; severe, $\geqslant 12$ points

Table is modified from previous publication on femoral lengthening over nail 8

Table II. Tibial lengthening outcome score - addition table.

\begin{tabular}{|c|c|c|c|c|}
\hline & Excellent $=\mathbf{2 5}$ & Good $=20$ & Fair $=10$ & Poor $=0$ \\
\hline Ankle & $10^{\circ}$ or $90 \%$ of pre-op & 0 to $10^{\circ}$ & $<10^{\circ}$ equinus, $>50 \%$ of pre-op & $>10^{\circ}$ equinus, $<50 \%$ of pre-op \\
\hline Lengthening & Within $1 \mathrm{~cm}$ of goal & Within $1.1 \mathrm{~cm}$ to $3 \mathrm{~cm}$ of goal & Within $3.1 \mathrm{~cm}$ to $5 \mathrm{~cm}$ of goal & $>5 \mathrm{~cm}$ of goal \\
\hline Gait (pre-op to post-op) & $\mathrm{L}-0$ to $\mathrm{L}-0$ or $\mathrm{L}-1$ to $\mathrm{L}-0$ & $\mathrm{~L}-2$ to $\mathrm{L}-1$ or $\mathrm{L}-1$ to $\mathrm{L}-1$ & $\mathrm{~L}-0$ to $\mathrm{L}-1$ or $\mathrm{L}-1$ to $\mathrm{L}-2$ or $\mathrm{L}-2$ to $\mathrm{L}-2$ & $\mathrm{~L}-0$ to $\mathrm{L}-2$ \\
\hline $\operatorname{MPTA}\left({ }^{\circ}\right)$ & 85 to 90 & 82 to 84 or 91 to 93 & 79 to 81 or 94 to 96 & $<79$ or $>96$ \\
\hline
\end{tabular}

Gait: L-0, no limp; L-I, slight limp; L-2, moderate limp

Pre-op, pre-operative; post-op, post-operative; MPTA, medial proximal tibial angle

Final result: Excellent, 95 to 100; Good, 75 to 94; Fair, 40 to 74; Poor, < 40

Table III. Tibial lengthening outcome score - subtraction table.

\begin{tabular}{llll}
\hline & Excellent $\mathbf{0} \mathbf{0}$ & Good $=\mathbf{5}$ & Fair $=\mathbf{2 0}$ \\
\hline Pain (pre-op to post-op) & P-0,1,2 to P-0; P-1 to P-1 & P-0 to P-1; P-2,3 to P-1 & P-1 to P-2; P-2 to P-3 \\
$\begin{array}{llll}\text { Activity or Work ability } \\
\text { (pre-op to post-op) }\end{array}$ & A/W-0 to A/W-0; A/W-1,2 & A/W-1 to A/W-1; A/W-2 & A/W-1 to A/W-2; A/W-0 \\
\hline
\end{tabular}

Pain: P-0, no pain; P-I, light pain; P-2, moderate pain; P-3, severe pain

Activity (A) or work ability (W): A/W-0, full activity and full time work; A/W-I, reduced activity and reduced work; A/W-2, no activity or no work

Pre-op, pre-operative; post-op, post-operative

Final result: Excellent, 95 to 100; Good, 75 to 94; Fair, 40 to 74; Poor, < 40

fixation treatment time. For both groups, the radiographic consolidation time begins at the osteotomy date and ends at the consolidation end point: it includes both distraction and consolidation phases. It is important to measure and compare the radiographic consolidation time in both groups as the bone is not healed in the LON group at the time the fixator is removed. The presence of a nail does not interfere in this evaluation. The radiographic consolidation index (radiographic consolidation time per centimeter of distraction gap) was calculated for both groups and compared, as well as the external fixation index (external fixation treatment time in months per lengthening in $\mathrm{cm}$ ).

During follow-up visits, we evaluated the effect of the amount lengthened on the MPTA, the posterior proximal tibial angle, the lateral distal tibial angle, and the anterior distal tibial angle

All matched variables (except cost) were evaluated for statistical significance using a paired student $t$-test. The cost data were compared using an unpaired $t$-test. A $p$-value $<0.01$ was considered statistically significant. 
LON operative technique

Step 1: fibular osteotomy. The patient is supine on a radiolucent table. This is carried out under tourniquet control through a $2 \mathrm{~cm}$ to $3 \mathrm{~cm}$ lateral incision at the junction of the middle and distal third of the fibula through the interval between the soleus and peroneal muscles.

Step 2: intramedullary nail insertion and tibial osteotomy. In order to diminish the canal pressure, and thereby the risk of fat embolism during reaming of the intact tibia, it is important to vent the diaphysis. ${ }^{21}$ This is accomplished by drilling several holes that are $4.8 \mathrm{~mm}$ in diameter, at the level of the intended osteotomy. This has the additional benefit of allowing reaming to escape and function as prepositioned bone graft. The standard parapatellar tendon approach is used. The tibial canal is reamed over a guide wire to a total of $2.0 \mathrm{~mm}$ larger than the diameter of the nail (usually either $8.5 \mathrm{~mm}$ or $10 \mathrm{~mm}$ ). The tourniquet should not be elevated during reaming, in order to allow better heat dissipation.

The level of the osteotomy is pre-planned on the radiograph to ensure that at least $5 \mathrm{~cm}$ of nail length are on the distal side of the distraction gap at the end of lengthening. The guide wire is withdrawn proximal to the planned osteotomy level. Through a $1 \mathrm{~cm}$ anterior skin incision, a $5 \mathrm{~mm}$ wide region of periosteum on the medial and lateral surfaces is elevated. A corticotomy is performed using either Ilizarov's classical technique ${ }^{22}$ or the percutaneous drill hole technique. ${ }^{23}$ Alternatively, a Gigli saw cut ${ }^{24}$ can be performed. It is not recommended to use a Gigli saw in hard cortical diaphyseal bone, as it generates too much heat and leads to poor bone formation. The guide wire is re-inserted into the tibia, and the nail length is measured. The nail length should end about $2.5 \mathrm{~cm}$ above the ankle joint to allow distal fixation with two wires. The nail is inserted and locked proximally with two interlocking screws using the standard interlocking guides. If a nail with oblique proximal interlocking screws is used, the interlocking guide may sometimes be slightly rotated to capture the upper end of the fibula. Alternatively, the upper tibiofibular joint can be stabilised with a solid cortical screw, or with a tensioned transfixion wire. The distal tibial fibular syndesmosis is stabilised with a $4.5 \mathrm{~mm}$ solid cortical bone screw.

Step 3: application of the external fixator. With the nail in place and the osteotomy completed, an external fixator (Ilizarov circular external fixator or monolateral rail) is applied for lengthening. The pins and wires are carefully positioned so that they do not come into contact with the intramedullary nail. The space between the intramedullary nail and each pin/wire should be at least $2 \mathrm{~mm}$ (more space is preferred).

Ilizarov fixator - (Figs 1a to 1c) A frame consisting of three rings sized to allow two finger breadths of clearance circumferentially around the calf is preconstructed. Guided by the image intensifier, a $1.8 \mathrm{~mm}$ bayonet-tipped long transverse llizarov wire is inserted perpendicular to the nail, approximately $1 \mathrm{~cm}$ behind to the upper end of the nail and $15 \mathrm{~mm}$ to $20 \mathrm{~mm}$ below the knee joint. With the use of fluoroscopy, the wire on the lateral view is checked to make sure it is not in contact with the nail. The threering frame is suspended from this reference wire and tensioned to $130 \mathrm{~kg}$. If properly aligned, the lengthening rods are parallel to the intramedullary rod. The distal ring should be $1 \mathrm{~cm}$ above the ankle joint. In the distal tibia, one transverse and one medial face tibial wire are inserted into the tibia and tensioned to $130 \mathrm{~kg}$. Alternatively, one of the distal wires may be used to capture the fibula and tibia together, thus stabilising the syndesmosis. The frame should be adjusted in the sagittal plane before attaching these wires to ensure parallelism between the lengthening rods and the rod in the sagittal plane. Using a Rancho cube (Smith \& Nephew, Memphis, Tennessee) and a $4.8 \mathrm{~mm}$ drill bit, a $6 \mathrm{~mm}$ half-pin is suspended off the upper ring by the proximal tibia. To make sure that the half-pin does not contact the nail, its position is checked with the image intensifier. Passing a $1.8 \mathrm{~mm}$ wire first and checking its position with the image intensifier is one way to ensure no contact. If the wire is at least $3 \mathrm{~mm}$ from the rod, a $4.8 \mathrm{~mm}$ cannulated drill bit followed by a $6 \mathrm{~mm}$ pin can be used. For additional stability, another half-pin may be added proximally. With no wires or pins, the middle ring acts to stabilise the construct by eliminating uninterrupted long threaded rods. The frame may be extended to the foot with the ankle positioned in neutral to prevent equinus from developing during lengthening.

Orthofix fixator (Orthofix, Inc., McKinney, Texas) (Figs 2a to 2c) A monolateral external fixation system (Limb Reconstruction System, $400 \mathrm{~mm}$ lengthener) is applied. When inserting the most proximal and distal $6 \mathrm{~mm}$ half-pins in the posterior part of the tibia, use the wire/cannulated drill technique and make sure that the half pins are placed parallel to each other and perpendicular to the nail. When inserting the second proximal and second distal half-pins, choose an appropriate level based on the space available and the spacing of the Orthofix pin clamp. It is helpful to plan the placement of the four pins by pre-operatively checking lateral radiographs. The distal pin should not be in contact with the tibial fibular syndesmotic screw.

Aftercare. The ankle is splinted in dorsiflexion with an orthotic that has Velcro straps to pull the foot up. The Velcro straps connect to the Ilizarov rings or to an arch that can be piggybacked onto the monolateral fixator. Distraction is begun at $0.25 \mathrm{~mm}$ four times per day, seven days post-operatively. Daily physical therapy to maintain knee and ankle ROM should begin one to two days after surgery. In addition to one hour of supervised physical therapy per day, the patient should undertake knee and ankle ROM exercises at home. Only touch-down weight bearing with two crutches is permitted during the 

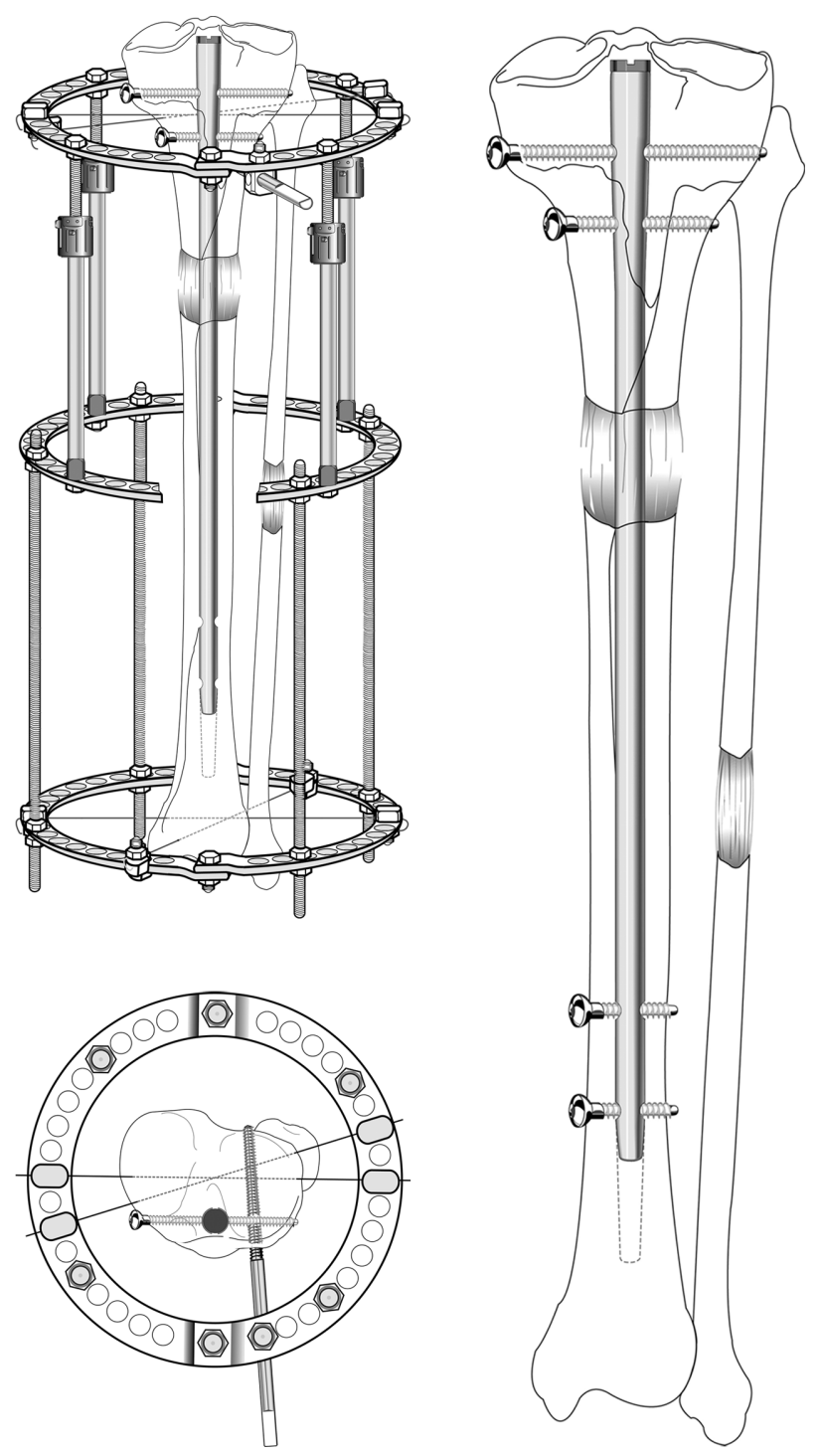

Fig. 1

Illustrations showing lengthening over a nail using a circular fixator. (top left) The osteotomy has been made and stabilised by the intramedullary rod, which is locked proximally. The llizarov frame requires only minimal fixation: two wires distally and two wires proximally plus a half-pin. It is important to transfix the fibula at each end either with wires or cortical bone screws. After gradual lengthening, the rod has risen up to the diaphyseal region; (bottom left) a bird's eye view of the proximal fixation. The wires (one of which captures the fibular head) and the half-pin are carefully inserted under control of the image intensifier to ensure that there is no contact between them and the intramedullary rod or its locking screws. Alternatively, the proximal and dista tibiofibular joints can be captured with independent bone screws. (right) The distal two interlocking screws are inserted to prevent shortening and the frame can be removed, leaving the rod as an internal stent, protecting the newly formed bone from bending, fracture, and deformation. Partial weight bearing is essential until there is complete consolidation. If the fibular regenerate bone is not healed at the time of frame removal, a cortical bone screw should be first inserted to stabilise the distal syndesmosis. Failure to do so may result in proximal migration of the distal fibula and disruption of the mortise. (Copyright 2015, Rubin Institute for Advanced Orthopedics, Sinai Hospital of Baltimore).

distraction phase. Radiographs are obtained every ten to 14 days to monitor distraction. For delayed bone formation, the rate of distraction should be slowed to $0.75 \mathrm{~mm}$ per day, or $0.5 \mathrm{~mm}$ per day.
After the lengthening goal is achieved, the patient returns to the operating room for the distal locking screws to be inserted into the tibia and the external fixator is removed (Fig. 3). To prevent loss of length, it is important to lock the nail before removing the fixator. The distal tibial fibular syndesmotic screw must remain in place to prevent proximal migration of the distal fibula, as tension from the immature regenerate bone tends to pull it proximally. The patient must continue using two crutches and partial weight bearing until the newly forming bone is bridged on at least two sides. After two cortices are completely bridged, full weight bearing with crutches is permitted in unilateral cases and 50\% weight-bearing in bilateral cases. In bilateral cases, full weight bearing without crutches is permitted once three intact cortices are seen. Hardware removal may be offered electively six to 12 months after complete healing, provided all four cortices have bridged.

\section{Results}

LON group. We performed 19 tibial LON procedures in 16 patients (seven male, nine female), three of whom had simultaneous bilateral tibial lengthening (Table IV). The mean follow-up time calculated from the first surgery was 23 months (nine to 52). The mean age was 27 years (15 to 62). The indications for lengthening were limb-length discrepancy in 13 patients and lengthening for stature in three patients. The aetiology of leg-length discrepancy or short stature was classified as congenital in five tibias, developmental (for example, leg-length discrepancy owing to growth arrest (post-fracture, sepsis, radiation, Blount disease, and avascular necrosis), spina bifida, KlippelTrenaunay syndrome, and short stature (owing to achondroplasia or growth hormone deficiency)) in nine tibias, and post-traumatic (secondary to acute shortening from fractures and post-tumour resection) in five tibias. In one patient, who had both a leg-length discrepancy and a posttraumatic nonunion of the distal tibia, the LON technique was used simultaneously to lengthen and achieve healing of the nonunion site. In another patient, both tibial and femoral LON procedures were performed simultaneously.

For the patients in the LON group, the difficulty levels for each lengthening were calculated as six mild, ten moderate, and three severe. Three patients had an acute correction of a tibial deformity at the time of the osteotomy. Orthofix monolateral fixators (Orthofix, McKinney, Texas) were used in two tibias, and Ilizarov circular fixators (Smith \& Nephew Orthopedics, Memphis, Tennessee) were used in the remaining 17 tibias. For those patients in whom we used the circular fixator, we included the entire foot in the frame in two, and the heel only in five patients (one who was a bilateral tibial lengthening patient). We injected the gastrocsoleus muscle with a Botulinum toxin (Allergan, Inc., Irvine, California) to prevent equinus contracture of the feet in one patient who had bilateral tibial lengthenings. 

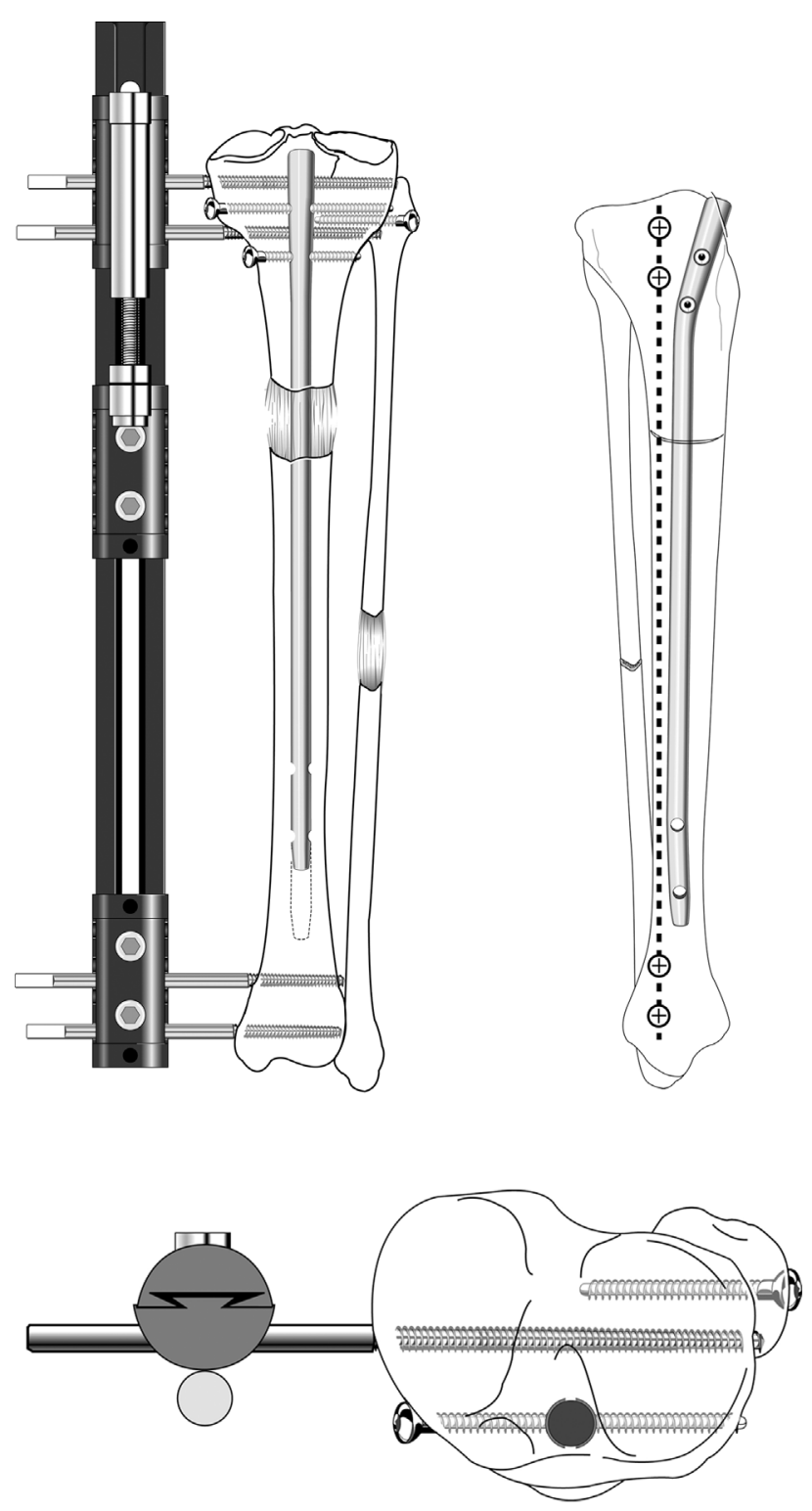

Fig. 2

Illustrations showing lengthening over a nail using a monolateral fixator. (top left) The nail is locked proximally. The proximal tibiofibular joint is captured by an independent bone screw. The distal tibiofibular joint is captured by a $4.5 \mathrm{~mm}$ cortical bone screw. During lengthening, the nail rises up. At the end of lengthening, the nail is locked distally. After frame removal, the newly formed bone matures under protection of the intramedullary rod; (bottom left) a bird's eye view of the monolateral fixator slightly posterior to the intramedullary nail. The proximal fibula is transfixed with an independent screw; (right) a sagittal view of the tibial bone showing the position of the intramedullary nail in relation to the external fixator pins before lengthening has started (copyright 2015, Rubin Institute for Advanced Orthopedics, Sinai Hospital of Baltimore).

Ace nails (Ace Medical Company, Los Angeles, California) were used in ten cases, and Russell-Taylor Delta tibial nails (Smith \& Nephew Orthopedics, Memphis, Tennessee) were used in seven cases. In the two remaining cases, an AO nail (Synthes, Paoli, Pennsylvania) and a Gross-Kempf nail (Howmedica, Rutherford, New Jersey) were already in place from previous surgeries and were therefore used for lengthening. Except for one case, all nails were inserted and locked proximally, and at the time of fixator removal, the nails were locked distally. In the one case, the nail was inserted retrograde from the heel to obtain an ankle fusion and was later locked proximally.

There were six additional surgeries at the time of frame application in the LON group: three tarsal tunnel decompressions, two Achilles tendon lengthenings, and one flexor digitorum longus tendon lengthening.

The tibial osteotomy was achieved with a percutaneous technique by using a Gigli saw in 12 cases, a modified percutaneous multiple drill hole technique in four cases, and the classical llizarov corticotomy with an osteotome in three cases. The tibial osteotomy level was at the metaphyseal-diaphyseal junction in two tibias, purely diaphyseal in 13 tibias, and metaphyseal in three tibias. In one tibia, no osteotomy was performed as the lengthening was achieved through a gradual distraction of a nonunion site that was percutaneously drilled.

In total, 12 patients were asked to donate blood before surgery, considering the potential blood loss caused by reaming the intramedullary canal of the tibia. None of the patients in the matched case group were asked to predeposit autologous blood.

llizarov group. The llizarov tibial lengthening matched case group consisted of 17 patients (11 male, six female) who had a total of 19 tibial lengthenings using only circular external fixation. All patients were followed prospectively for a minimum of two years. The mean age of the patients in this group was 27 years (13 to 54). The indications for lengthening were leg-length discrepancy in 15 patients, and lengthening for stature in two patients (who underwent simultaneous bilateral tibial lengthening). The aetiology was classified as post-traumatic in nine cases, congenital in one case, and developmental in nine cases. In one patient who had both a leg-length discrepancy and a post-traumatic nonunion of the distal tibia, the Ilizarov technique was used to simultaneously lengthen the tibia through a proximal tibial osteotomy and achieve healing of the nonunion site. One patient had a simultaneous lengthening of the tibia and femur. In six patients, we performed a double-level osteotomy to obtain a bifocal lengthening. The tibial osteotomy was achieved by using a Gigli saw in four cases and a classical Ilizarov corticotomy with an osteotome in the remaining 15 cases. The osteotomy level was diaphyseal in two cases, metaphyseal in 14 cases, and metaphysealdiaphyseal in three cases. In ten patients, we included the entire foot in the frame. The pre-operative levels of difficulty were calculated as six mild, ten moderate, and three severe.

Outcomes. All the patients in both groups, including the two distal tibial nonunions, achieved a complete consolidation of the new bone. The mean lengthening was $5.2 \mathrm{~cm}$ (2.0 to 10.2) in the LON group and $4.9 \mathrm{~cm}$ $(1.3 \mathrm{~cm}$ to $12.5 \mathrm{~cm})$ in the matched case group. The mean 

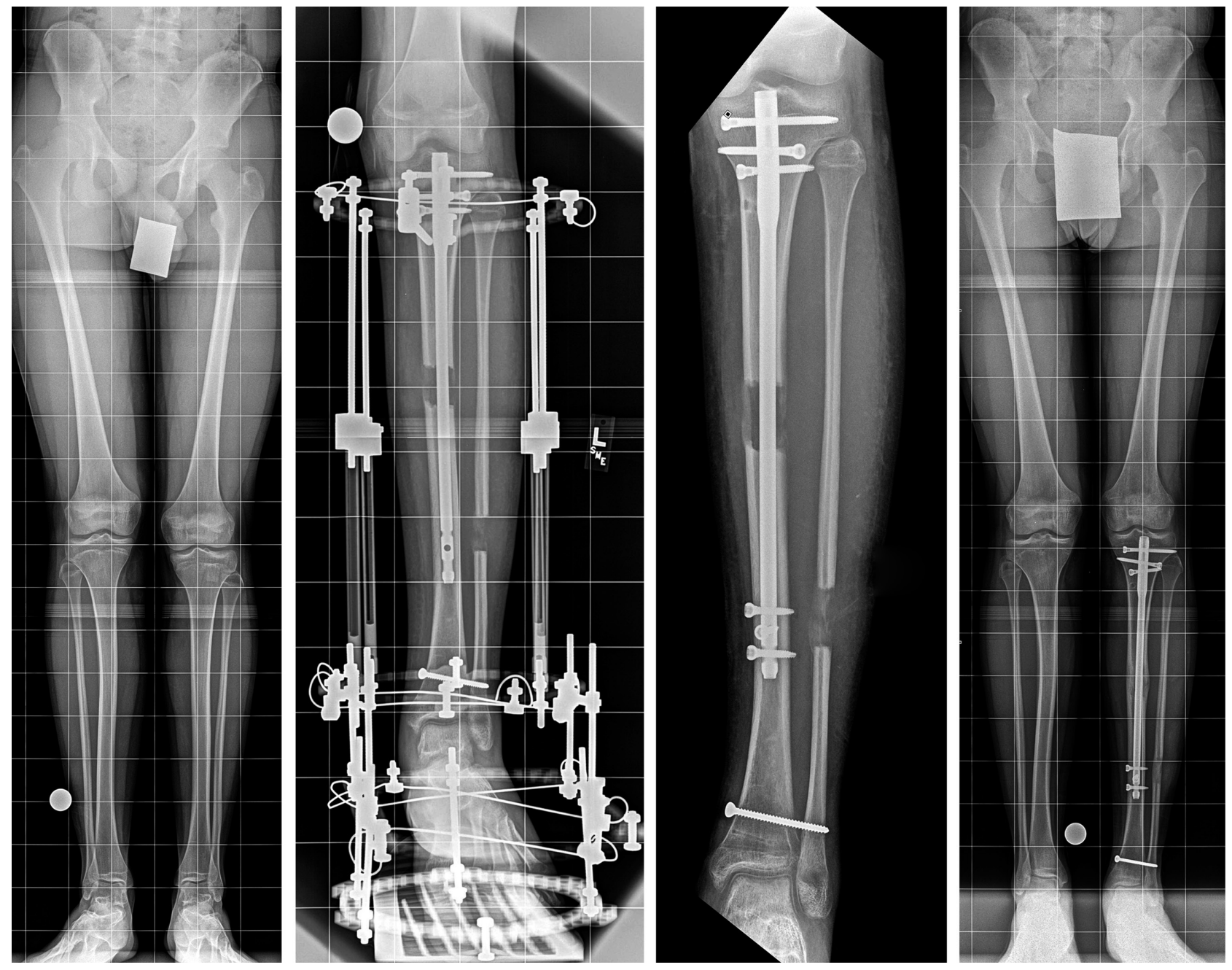

Fig. 3

Radiographs of (left) a young man with a history of clubfoot and a $3 \mathrm{~cm}$ left tibial discrepancy (second left) obtained after lengthening by $3 \mathrm{~cm}$. The external fixation spans the ankle to prevent equinus, and the distal tibial fibular syndesmosis is transfixed with a bone screw. The nail rises up during lengthening, but it still has sufficient length in the distal segment for stability; (second right) showing nail is locked distally, and external fixation is removed. The distal tibial fibular screw prevents proximal migration of the distal fibula; and (right) obtained four months after nail is locked showing that complete healing has been achieved (copyright 2015, Rubin Institute for Advanced Orthopedics, Sinai Hospital of Baltimore).

external fixation time in the LON group was 2.6 months (1.4 to 3.8) and 7.6 months (four to 18) for patients in the matched case group. The difference in external fixation times was significant $(p=0.004)$. In two LON patients, the external fixator was not removed immediately at the end of the distraction phase in order to provide additional temporary support for a long distraction gap. The mean external fixation index was 0.7 months per $\mathrm{cm}(0.5$ to 1.1) for the LON group and 2.3 months per $\mathrm{cm}$ ( 1.1 to 8.1) in the matched case group. The difference in the external fixation index between the two groups was significant $(p=0.009)$. The mean radiographic consolidation time, determined in 15 LON cases, was 6.6 months (four to ten). Four cases did not have a sufficient number of radiographs to determine the radiographic consolidation time. The matched case group had a mean radiographic consolidation time of 7.6 months (4 to 18). The difference in the radiographic consolidation time between the two groups was not significant $(p=0.7)$. The radiographic consolidation index was 1.4 months per $\mathrm{cm}$ (0.7 to 3.4) in the LON group and 2.3 months per $\mathrm{cm}$ (1.1 to 8.1) for the matched case group. This difference in the radiographic consolidation index was not significant $(p=0.15)$.

There were no evident differences in the mechanical axis displacement owing to the lengthening with circular fixation. The monolateral fixator tended to push the lengthened tibia into slight valgus, which resolved after locking the nail and removing the fixator. The mean cost for patients in the LON group was $\$ 30802$ (\$25 946 to $\$ 42202$ ) while the mean cost for patients in the matched case group was $\$ 20480$ ( $\$ 15500$ to $\$ 27875$ ). This cost difference was significant with $p<0.0001$. Mean operative time was four hours (three to seven) for the LON group and 4.6 hours (2.7 to 6.0 ) for the matched case 
Table IV. Patient demographics.

\begin{tabular}{|c|c|c|c|c|c|c|c|c|c|c|}
\hline \multirow[b]{2}{*}{ No. of pair } & \multicolumn{2}{|c|}{ Age (yrs) } & \multicolumn{2}{|c|}{ Aetiology } & \multicolumn{2}{|c|}{ Difficulty level } & \multicolumn{2}{|c|}{$\begin{array}{l}\text { Amount } \\
\text { lengthened (cm) }\end{array}$} & \multicolumn{2}{|c|}{ Result } \\
\hline & LON & Matched case & LON & Matched case & LON & Matched case & LON & Matched case & LON & Matched case \\
\hline 1 & 27 & 34 & $\mathrm{~T}$ & $\mathrm{~T}$ & Mild & Mild & 2.5 & 2.0 & E & $E$ \\
\hline 2 & 29 & 39 & $\mathrm{D}$ & $\mathrm{D}$ & Moderate & Moderate & 2.8 & 2.0 & $E$ & $E$ \\
\hline 3 & 15 & 14 & C & $\mathrm{C}$ & Mild & Mild & 3.6 & 3.5 & $E$ & $E$ \\
\hline 4 & 28 & 34 & $\mathrm{C}$ & $\mathrm{T}$ & Mild & Mild & 3.0 & 4.5 & $E$ & $E$ \\
\hline 5 & 18 & 24 & $\mathrm{D}$ & $\mathrm{D}$ & Severe & Severe & 10.2 & 12.5 & $E$ & $\mathrm{E}$ \\
\hline 6 & 18 & 24 & $\mathrm{D}$ & $\mathrm{D}$ & Severe & Severe & 10.1 & 12.5 & $E$ & G \\
\hline 7 & 29 & 25 & $\mathrm{~T}$ & $\mathrm{~T}$ & Mild & Mild & 2.0 & 1.8 & $E$ & $\mathrm{E}$ \\
\hline 8 & 34 & 28 & $\mathrm{D}$ & $\mathrm{D}$ & Moderate & Moderate & 3.0 & 1.3 & $E$ & $E$ \\
\hline 9 & 62 & 54 & $\mathrm{~T}$ & $\mathrm{~T}$ & Moderate & Moderate & 4.9 & 2.9 & $E$ & $E$ \\
\hline 10 & 20 & 16 & $\mathrm{D}$ & $\mathrm{T}$ & Moderate & Moderate & 5.1 & 3.8 & $E$ & G \\
\hline 11 & 45 & 38 & $\mathrm{~T}$ & $\mathrm{~T}$ & Moderate & Moderate & 3.8 & 4.2 & $E$ & G \\
\hline 12 & 18 & 20 & $C$ & $\mathrm{D}$ & Moderate & Moderate & 7.9 & 9.3 & $E$ & $\mathrm{E}$ \\
\hline 13 & 18 & 20 & $C$ & D & Moderate & Moderate & 8.0 & 9.2 & $E$ & $\mathrm{E}$ \\
\hline 14 & 34 & 29 & $C$ & $\mathrm{~T}$ & Mild & Mild & 2.3 & 3.0 & $E$ & $E$ \\
\hline 15 & 54 & 35 & $\mathrm{D}$ & $\mathrm{D}$ & Severe & Severe & 6.5 & 4.8 & G & G \\
\hline 16 & 29 & 27 & D & D & Moderate & Moderate & 3.0 & 2.0 & $E$ & $\mathrm{E}$ \\
\hline 17 & 27 & 25 & $\mathrm{~T}$ & $\mathrm{~T}$ & Moderate & Moderate & 4.3 & 3.7 & $E$ & $E$ \\
\hline 18 & 19 & 13 & $\mathrm{D}$ & $\mathrm{D}$ & Moderate & Moderate & 3.2 & 1.7 & $E$ & $\mathrm{E}$ \\
\hline 19 & 22 & 27 & $\mathrm{D}$ & $\mathrm{T}$ & Mild & Mild & 3.0 & 2.2 & G & $G$ \\
\hline
\end{tabular}

LON, lengthening over nail; T, post-traumatic; D, developmental; C, congenital; E, excellent; G, good

group. The difference between the two groups with respect to operative time was not significant $(p=0.63)$. The mean blood loss for the LON group was $280 \mathrm{ml}$ (100 to 600 ) and $100 \mathrm{ml}$ (30 to 200) for the matched case group. The difference in blood loss was significant $(p=0.004)$. Four LON patients received an autologous blood transfusion post-operatively, whereas none of the patients in the matched case group needed this additional intervention. The rate of additional unplanned surgeries for the LON group was $31 \%$, while that for the matched case group was $42 \%$. This was not significant $(p=0.58)$.

\section{Complications}

All 16 LON patients developed superficial pin infections and were treated with oral cefazolin (500 milligrams four times per day for ten days). Four patients developed deep infections at the pin site locations and were treated with debridement and intravenous antibiotics. Two of these four patients had their pins removed. All the patients in the matched case group also developed superficial pin infections and were treated successfully with cefazolin (as above). No patients in the matched case group developed deep infections.

One LON patient, who had undergone a previous femoral lengthening, developed peroneal nerve palsy during the tibial lengthening. This completely resolved after surgical decompression at the neck of the fibula. Three patients in the matched case group developed signs of peroneal nerve neuropraxia during the lengthening process, and all recovered with decompression.

One LON patient, who underwent simultaneous tibial and femoral lengthening, broke a proximal tibial Kirschner wire which was replaced. This same patient went on to develop a progressive knee subluxation which resolved by using a dynamic knee extension splint. Another LON patient, who had a delayed consolidation of eight months, broke the distal nail locking screw, which was subsequently removed. In a third LON patient, who had a lengthening of $10.2 \mathrm{~cm}$, we switched a loose proximal locking screw to a longer screw. One LON patient developed a symptomatic heterotopic ossification at the proximal end of the nail close to the patellar tendon. Removing the nail resolved the symptoms in this patient.

The rates of the complications classified as problems, obstacles, and sequelae are as follows: the LON group had $49 \%$ problems, $29 \%$ obstacles, and $22 \%$ sequelae; the matched case group had $48 \%$ problems, $37 \%$ obstacles, and $15 \%$ sequelae. The difference in problems, obstacles, and sequelae between the LON group and the matched case group was not significant (problems: $p=0.58$, obstacles: $p=0.34$, sequelae: $p=0.34$ ). Two LON patients developed valgus deformity of $4^{\circ}$ as sequelae; three matched case patients developed a $3^{\circ}$ valgus deformity as sequelae.

Functional outcomes. Full weight-bearing for patients in both groups was permitted after a mean of 4.8 months (2.6 to 6.8). All patients in both groups regained their pre-operative knee and ankle ROM. The mean total arc of movement for the ankle pre-operatively in the LON patients was $49^{\circ}$ while post-operatively it was $54^{\circ}$ $(p=0.33)$. For the matched case patients, the mean preoperative ankle total arc of movement was $49^{\circ}$, while post-operatively it was $50^{\circ}(p=0.85)$.

In the LON group, the tibial lengthening outcome score was excellent in 17 cases and good in two cases (Table IV). In the matched case group, the outcome score was excellent in 14 cases and good in five cases. 
Seven cases in the matched case group had improvements in gait after treatment - four cases improved from a slight limp to no limp and three cases improved from a moderate limp to a slight limp. Two cases had no limp before treatment and had a slight limp after treatment. Five cases had no change in gait after treatment with the Ilizarov method - one case had a slight limp that remained after treatment and four cases had no limp.

Gait improved in 12 cases that had LON treatment: four cases improved from a slight limp to no limp, seven cases improved from a moderate limp to a slight limp, and one case improved from a moderate limp to no limp. Seven cases had no change in gait before and after LON treatment - two cases had a slight limp and five cases had no $\operatorname{limp}$.

In three LON patients, we corrected axial deviations that developed during the lengthening by using external hinges placed on the circular frame. Seven patients in the matched case group developed axial deviation during lengthening.

\section{Discussion}

The concept of combining external fixation lengthening with an intramedullary rod is not new. Other authors have used intramedullary nails to maintain alignment during acute or gradual lengthening. ${ }^{25,26}$ The nails used in this manner have usually had a small diameter and were not able to be locked into place. Also, the intramedullary canals were not reamed at the time of nail insertion. We chose, however, to combine external fixation with a locked intramedullary nail to maintain alignment, allow for early removal of the external fixator, and to help prevent fractures.

In this retrospective chart review, we did not identify any patients with complaints of anterior knee/patellar tendon pain. While this has been reported in tibial nailing procedures, we did not see this in our patient population. Nonetheless, we do routinely recommend elective rod removal, especially in younger patients.

The three main advantages of the LON technique are reducing the duration of treatment with external fixation, preventing fracture of the new bone, and restoring knee and ankle ROM more quickly.

In large lengthening procedures, the risk of nail breakage is higher. Kristiansen and Steen ${ }^{20}$ reported nine consecutive patients treated for short statue. They reported that only three lengthening segments proceeded without major complications (e.g., nail breakages, deep osteomyelitis) and stated that because of this high number of complications, the authors returned to the traditional callotasis lengthening technique. To prevent complications, we suggest leaving the external fixator in place in long lengthening procedures until the newly formed bone in the distraction gap shows evidence of early bridging. To prevent premature consolidation, the intramedullary canal is over reamed by $2 \mathrm{~mm}$ and the patient is allowed only touch-down weight bearing during the distraction phase. Over reaming also makes it less likely for the nail to bind in a tight canal. The negative effect on bone circulation from reaming is temporary. ${ }^{27}$ In very short tibias, as would be seen in dwarfism, the rod may not have enough distal purchase. In such cases, we recommend the lengthening and then nailing technique described by Rozbruch et al, ${ }^{13}$ rather than LON.

The potential disadvantages of the LON technique include problems with retained nails and increased risk of blood loss, fat embolism, and intramedullary infection. $8,9,11,13,14,16-20$ To avoid infections, care is taken to ensure that there is no contact between the nail and the external fixation pins. Other authors have had reasonably low rates of re-fracture when using intramedullary rods after external fixation, even when no attempt was made to insert the external fixation pins outside the nail track. ${ }^{28,29}$

Tibial LON in children is contraindicated due to the risk of causing proximal tibial growth arrest. It is possible that a small-diameter nail locked distal to the growth plate can allow progressive growth. ${ }^{17}$ We believe that the ideal patients for this technique include adults with leg-length discrepancy or short stature without large deformities. If a patient has moderate proximal tibial varus, the deformity can be corrected acutely and the tibia can be lengthened over the nail. Contraindications are, as previously noted, deep infection or an unfavourable soft-tissue situation. Accurate pre-operative planning is essential. ${ }^{30}$ However, acute correction of significant valgus deformities is inadvisable because of the risk of stretching the peroneal nerve. Peroneal nerve decompression is necessary in such cases.

One of the strengths of this study is that it is the only case-matched series on tibial LON available in the literature. The main weakness of our study is that it is retrospective and subject to inherent biases such as recall bias, selection bias, and outcomes bias. Another limitation of this study is that we compare two techniques that were used at different times. Furthermore, the current study has a small sample size, which could result in Type II error. Potentially, the best way to boost the power of the statistical analysis and minimise the type II error is to increase the sample size in further studies.

We consider the LON method to be an attractive alternative to that of fully-implantable self-lengthening telescopic nails. ${ }^{31-34}$ However, these newer automated telescopic nails are very expensive, some types are difficult to control, and most are not approved by the Food and Drug Administration and are therefore unavailable for use in the United States. The relatively low cost of trauma nails, combined with re-useable circular external fixators to achieve LON is particularly attractive for the developing world, where cost is a key factor in device/ technique selection. 


\section{References}

1. Aquerreta JD, Forriol F, Cañadell J. Complications of bone lengthening. Int Orthop 1994;18:299-303.

2. De Bastiani G, Aldegheri R, Renzi-Brivio L, Trivella G. Limb lengthening by callus distraction (callotasis). J Pediatr Orthop 1987;7:129-134.

3. Ilizarov GA. Clinical application of the tension-stress effect for limb lengthening. Clin Orthop Relat Res 1990;250:8-26.

4. Karger C, Guille JT, Bowen JR. Lengthening of congenital lower limb deficiencies. Clin Orthop Relat Res 1993;291:236-245.

5. Paley D. Current techniques of limb lengthening. J Pediatr Orthop 1988;8:73-92.

6. Fischgrund J, Paley D, Suter C. Variables affecting time to bone healing during limb lengthening. Clin Orthop Relat Res 1994;301:31-37.

7. Paley D. Problems, obstacles, and complications of limb lengthening by the llizarov technique. Clin Orthop Relat Res 1990;250:81-104.

8. Paley D, Herzenberg JE, Paremain G, Bhave A. Femoral lengthening over an intramedullary nail. A matched-case comparison with llizarov femoral lengthening J Bone Joint Surg [Am] 1997;79-A:1464-1480.

9. Ba Linh H, Feibel RJ. Tibial lengthening over an intramedullary nail. Tech Orthop 2009;24:279-288.

10. Bilen FE, Kocaoglu M, Eralp L, Balci HI. Fixator-assisted nailing and consecutive lengthening over an intramedullary nail for the correction of tibial deformity. J Bone Joint Surg [Br]2010;92-B:146-152.

11. Kocaoglu M, Eralp L, Bilen FE, Balci HI. Fixator-assisted acute femoral deformity correction and consecutive lengthening over an intramedullary nail. J Bone Joint Surg [Am]2009;91-A:152-159.

12. Eralp L, Kocaoglu M. Distal tibial reconstruction with use of a circular external fixator and an intramedullary nail. Surgical technique. J Bone Joint Surg [Am] 2008;90-A(Suppl 2 Pt 2):181-194

13. Rozbruch SR, Kleinman D, Fragomen AT, Ilizarov S. Limb lengthening and then insertion of an intramedullary nail: a case-matched comparison. Clin Orthop Relat Res 2008;466:2923-2932.

14. Park HW, Yang KH, Lee KS, et al. Tibial lengthening over an intramedullary nail with use of the llizarov external fixator for idiopathic short stature. J Bone Joint Surg [Am]2008;90-A:1970-1978.

15. Min WK, Min BG, Oh CW, et al. Biomechanical advantage of lengthening of the femur with an external fixator over an intramedullary nail. J Pediatr Orthop $B$ 2007;16:39-43.

16. Watanabe $\mathbf{K}$, Tsuchiya $\mathbf{H}$, Sakurakichi $\mathbf{K}$, et al. Tibial lengthening over an intramedullary nail. J Orthop Sci2005;10:480-485.

17. Saraph V, Roposch A, Zwick EB, Linhart WE. Tibial lengthening over nails in children using modified Ender nails: preliminary results of a new treatment. J Pediatr Orthop B2004;13:383-388.

18. Kocaoglu M, Eralp L, Kilicoglu O, Burc H, Cakmak M. Complications encountered during lengthening over an intramedullary nail. J Bone Joint Surg [Am] 2004;86-A:2406-2411.

19. Simpson AH, Cole AS, Kenwright J. Leg lengthening over an intramedullary nail. J Bone Joint Surg [Br] 1999;81-B:1041-1045.

20. Kristiansen LP, Steen H. Lengthening of the tibia over an intramedullary nail, using the llizarov external fixator. Major complications and slow consolidation in 9 lengthenings. Acta Orthop Scand 1999;70:271-274.

21. Wozasek GE, Simon P, RedI H, Schlag G. Intramedullary pressure changes and fat intravasation during intramedullary nailing: an experimental study in sheep. J Trauma 1994;36:202-207.

22. Schwartsman V, Schwartsman R. Corticotomy. Clin Orthop Relat Res 1992;280: 37-47.
23. Paley D. The llizarov corticotomy. Tech Orthop 1990:5:41-52

24. Paley D, Tetsworth K. Percutaneous osteotomies. Osteotome and Gigli saw techniques. Orthop Clin North Am 1991;22:613-624.

25. Bost FC, Larsen LJ. Experiences with lengthening of the femur over $n$ intramedullary rod. J Bone Joint Surg [Am] 1956;38-A:567-584

26. Raschke MJ, Mann JW, Oedekoven G, Claudi BF. Segmental transport after unreamed intramedullary nailing. Preliminary report of a "Monorail" system. Clin Orthop Relat Res 1992;282:233-240.

27. Klein MP, Rahn BA, Frigg R, Kessler S, Perren SM. Reaming versus non-reaming in medullary nailing: interference with cortical circulation of the canine tibia. Arch Orthop Trauma Surg 1990;109:314-316.

28. Riemer BL, Butterfield SL. Comparison of reamed and nonreamed solid core nailing of the tibial diaphysis after external fixation: a preliminary report. J Orthop Trauma 1993;7:279-285.

29. Wheelwright EF, Court-Brown CM. Primary external fixation and secondary intramedullary nailing in the treatment of tibial fractures. Injury 1992;23:373-376.

30. Paley D, Herzenberg JE, Tetsworth K, McKie J, Bhave A. Deformity planning for frontal and sagittal plane corrective osteotomies. Orthop Clin North Am 1994;25:425-465

31. Baumgart R, Betz A, Schweiberer L. A fully implantable motorized intramedullary nail for limb lengthening and bone transport. Clin Orthop Relat Res 1997;343:135-143

32. Bliskunov Al. Lengthening of the femur using implantable appliances. Acta Chir Orthop Traumatol Cech 1984;51:454-466. (In Czech)

33. Guichet JM, Grammont PM, Trouilloud P. A nail for progressive lengthening. An animal experiment with a 2-year follow-up. Chirurgie 1992;118:405-410. (In French)

34. Cole JD, Justin D, Kasparis T, DeVlught D, Knobloch C. The intramedullary skeletal kinetic distractor (ISKD): first clinical results of a new intramedullary nail for lengthening of the femur and tibia. Injury 2001;32(Suppl 4):SD129-139.

Funding Statement:

No authors received payment or funding for any aspect of this study.

Author Contribution:

R. D. Burghardt: Data collection and analysis, performed substantial revisions to the manuscript, and reviewed and approved the final manuscript.

A. Manzotti: Study design, performed data collection and analysis, wrote the manuscript, and reviewed and approved the final manuscript.

- A. Bhave: Study design, performed data collection and analysis, and reviewed and approved the final manuscript.

D. Paley: Study design, performed data collection and analysis, and reviewed and approved the final manuscript.

J. E. Herzenberg: Study design, performed data collection and analysis, performed substantial revisions to the manuscript, and reviewed and approved the final manuscript.

ICMJE conflict of interest:

- J. E. Herzenberg is a paid consultant for OrthoPediatrics, Orthofix, Smith \& Nephew, and Ellipse Technologies; and receives research support from Ellipse Technologies. A. Bhave is a paid consultant for DJ Orthopaedics, Merz GMB, On Going Care Solutions, and Orthosensor; receives IP royalties from Guardian, Inc. and is on the editorial board of the World Journal of Orthopaedics. D. Paley is a paid consultant for Ellipse Technologies; receives IP royalties from Smith \& Nephew, Ellipse Technologies, Inc., Pega Medical, and Ellipse Technologies and receives publishing royalties from Springer.

- The following companies supported an annual course at the institution of $A B$ and JEH: Acumed, Brainlab, DePuy Synthes, Ellipse Technologies, Integra, MHE Coalition, Orthofix, OrthoPediatrics, Smith \& Nephew, Stryker, and Zimmer Biomet. The following companies supported a non-profit organization that benefits the patients at the institution of AB and JEH: Stryker, Metro Prosthetics, CS Medical Supply Company.

(c) 2016 Burghardt et al. This is an open-access article distributed under the terms of the Creative Commons Attributions licence (CC-BY-NC), which permits unrestricted use, distribution, and reproduction in any medium, but not for commercial gain, provided the original author and source are credited. 